\title{
Synoviocyte-Packaged Chlamydia trachomatis Induces a Chronic Aseptic Arthritis
}

R.D. Inman ${ }^{\star} \ddagger$ and B. Chiu*

*The Toronto Hospital, and the ${ }^{\ddagger}$ Department of Medicine and Immunology, University of Toronto, Toronto, ON M5T 2S8

\begin{abstract}
The basic mechanisms underlying reactive arthritis and specifically the joint injury that follows intra-articular Chlamydia trachomatis infection have not been defined. The present study addresses this question through the development of an experimental model. Stable cell lines were generated from synoviocytes harvested from the knee joints of Lewis rats. The synoviocytes were cocultivated with $C$. trachomatis to allow invasion by the microbe and were then transferred by intra-articular injection into the knee joints of Lewis rats. The ensuing arthritis could be subdivided into an early phase ( $\leq 14 \mathrm{~d}$ ) and a late phase. The early phase was characterized by intense, primarily neutrophilic, synovitis; accelerated cartilage injury; dissemination of Chlamydia to liver and spleen; and viable Chlamydia in the joints. The late phase was marked by mixed mononuclear lymphocyte infiltration in the joint; dysplastic cartilage injury and repair; absence of viable organisms; and development of a distinctive humoral response. Western blot analysis comparing reactive arthritis patients to the experimental model indicates that candidate arthritogenic chlamydial antigens are comparable between the two. This model demonstrates that an intense synovitis can be induced by this intracellular pathogen, and that chronic inflammation can persist well beyond the culture-positive phase. Furthermore, these data show that the synoviocyte is a suitable host cell for $C$. trachomatis and can function as a reservoir of microbial antigens sufficient to perpetuate joint injury. (J. Clin. Invest. 1998. 102:1776-1782.) Key words: reactive arthritis • Chlamydia
\end{abstract}

\section{Introduction}

Reactive arthritis $(\operatorname{ReA})^{1}$ refers to an aseptic arthritis, which is precipitated by an extra-articular infection. The disease has attracted a great deal of research interest because it is a paradigm for a chronic rheumatic disease in which host immunogenetic susceptibility factors interact with a microbial trigger.

Address correspondence to R.D. Inman, M.D., The Arthritis Centre, The Toronto Hospital, 399 Bathurst Street, Toronto, Ontario M5T 2S8, Canada. Phone: 416-603-5144; FAX: 416-603-4348; E-mail: rinman@torhosp.toronto.on.ca

Received for publication 3 February 1998 and accepted in revised form 11 September 1998.

1. Abbreviations used in this paper: CFX, ciprofloxacin; CIA, Chlamydia-induced arthritis; H/E, hemotoxylin and eosin; mBSA, methylated bovine serum albumin; PMN, polymorphonuclear neutrophil; $\mathrm{ReA}$, reactive arthritis; TCY, tetracycline.

J. Clin. Invest.

(C) The American Society for Clinical Investigation, Inc. 0021-9738/98/11/1776/07 \$2.00

Volume 102, Number 10, November 1998, 1776-1782

http://www.jci.org
The dominant host factor is the class I HLA gene B27, which is present in $60-90 \%$ of such cases. The infections that initiate $\mathrm{ReA}$ are either gastrointestinal (with Salmonella, Shigella, Campylobacter, and Yersinia spp predominating) or genitourinary infections (with Chlamydia trachomatis predominating). There have been numerous mechanisms postulated to explain $\mathrm{ReA}$, including molecular mimicry, immune response to arthritogenetic peptide, immune complex formation, in situ antigen deposition, and toxin-mediated synovitis (1).

Although persisting intra-articular microbial antigens have been demonstrated for several pathogens $(2,3)$, in the case of Chlamydia-induced arthritis (CIA) the evidence is most compelling that "reactive arthritis" is a misnomer and that CIA in fact represents a form of septic arthritis. There is a sustained, local immune response to Chlamydia antigens in the joint (46). There is evidence supporting the persistence of Chlamydia in the joints by electron microscopy (7), immunoelectron microscopy (8), immunofluorescence (9), and demonstration of Chlamydia nucleic acids by PCR $(10,11)$, and ribosomal RNA hybridization techniques (12-14). There is also evidence that antibiotic treatment of CIA can modify the course of the disease $(15,16)$ to a greater extent than is seen in postdysenteric ReA (17). Finally, there is evidence that synovial fluid has no intrinsic microbicidal activity against Chlamydia, in contradistinction to its effects on gram-negative bacteria (18).

In view of the evidence that Chlamydia gains access to the joint and can persist for prolonged periods at the site, it is important to resolve what mechanisms mediate clearance of intra-articular Chlamydia and what alterations or defects in those mechanisms could account for the chronicity of CIA seen in some patients. To this end, we have developed an experimental model of CIA that allows a systematic analysis of the biological consequences of intra-articular Chlamydia.

\section{Methods}

Rats. Adult male Lewis rats (Harlan Sprague Dawley, Indianapolis, IN) were maintained in conventional housing in the animal facility until exposure to Chlamydia. Thereafter, they were kept in isolation.

Establishment of the rat fibroblast line. An adult male Lewis rat was immunized subcutaneously with $0.5 \mathrm{mg}$ of methylated BSA (mBSA; Sigma Chemical Co., St. Louis, MO) in $1 \mathrm{ml}$ of a 1:1 mixture of complete Freund's adjuvant and PBS. $7 \mathrm{~d}$ later, the animal was given the same dose of mBSA, again subcutaneously. $1 \mathrm{wk}$ later, the animal was anesthetized with Forane (Zenoca Pharma, Mississauga, ON, Canada) and injected intra-articularly in the knee joints with 0.1 $\mathrm{ml}$ of a sterile mBSA solution in PBS at $0.5 \mathrm{mg} / \mathrm{ml}$ (i.e., $50 \mu \mathrm{g} / \mathrm{knee}$ ). $48 \mathrm{~h}$ later, the knee joints were warm and swollen. The rat was euthanized in a carbon dioxide chamber. The knee joints were sterilely dissected, and inflamed synovial tissues removed. The tissues were carefully minced and cultured in 24-well plates using $\alpha$-MEM (GIBCO/ BRL, Grand Island, NY) supplemented with 20\% FCS. 10-14 d later, a number of fibroblast-like cells could be seen to have migrated out from the explant tissues. With time, these cells developed stable monolayers. They were removed with trypsin-EDTA (GIBCO/BRL) and seeded into flasks for expansion. Subsequently, they could be passaged repeatedly in this manner. Under these conditions, rat synovial fibroblasts usually show no sign of contact inhibition. They can 
grow beyond their confluent monolayer phase and form multilayer mats of cells. By a change of media once a week, these lines can be maintained for long periods of time.

Chlamydia. C. trachomatis serotype L2 was obtained from Dr. Martin Petric (Hospital for Sick Children, Toronto, ON, Canada). Frozen stocks were kept at $-70^{\circ} \mathrm{C}$. It is our experience that Chlamydia grows well in many kinds of adherent cell types, including HeLa cells, mouse L cells, and the synovial fibroblast lines. To generate infected cells, a 1-ml aliquot of frozen stock of Chlamydia was centrifuged onto a fresh monolayer of the appropriate target cells at $800 \mathrm{~g}$ for $30 \mathrm{~min}$. The infected cells were then incubated for $24-48 \mathrm{~h}$. When inclusion bodies within the cells had matured, synoviocytes were harvested by scraping the cells off the plastic surface with a cell scraper or by removing them enzymatically with trypsin-EDTA. Enumeration of Chlamydia CFUs was done by serial dilution. Serial dilutions of Chlamydia were centrifuged onto HeLa cell monolayers in 24-well plates in quadruplicate. Wells were examined under phasecontrast microscopy after $48 \mathrm{~h}$ of incubation to determine the end point. The end point is defined as the absence of inclusion bodies in all four wells of a particular dilution. The concentration of CFUs in the starting preparation can then be calculated.

Intra-articular injection of Chlamydia. After incubation with Chlamydia, the synoviocytes were harvested with trypsin and diluted in PBS. The inclusion body-laden synoviocytes survived the treatment well and were able to reattach if replated onto the plastic well. The final concentration was adjusted to $5 \times 10^{5} / \mathrm{ml}$ of viable cells. The rats were anesthetized with Forane, and $0.2 \mathrm{ml}$ of the infected cells containing $2 \times 10^{5}$ CFUs were injected into the knee joint using a $23 \mathrm{G}$ needle. All animals tolerated the procedure well. $2 \mathrm{~d}$ postinjection, the onset of swelling of the joint was observed. At various time periods after intra-articular injections, the animals were euthanized.

Processing of tissues. At necropsy, the knee joints were removed whole for histological evaluation. They were fixed in buffered formalin and decalcified before being blocked, sectioned, and stained with hematoxylin and eosin $(\mathrm{H} / \mathrm{E})$. The size of the joints were measured with a vernier caliper before decalcification. A $0.4 \mathrm{M}$ sodium citrate solution of water/formic acid (3:1) was used for decalcification.

For culture studies, knee joints were sterilely opened, and a small amount of sterile PBS was introduced into the joint space. The knees were lavaged and fluid aspirated for the detection of live Chlamydia. Synovial tissues from these joints were also removed and snap frozen in OCT compound (Miles Inc., Elkart, IN) using liquid nitrogen for immunofluorescent studies.

Internal organs, such as the spleen, liver, lung, and kidney, were removed for cultures and immunofluorescence. Small samples of tissue were snap frozen in OCT, and the remaining tissue was homogenized in sterile PBS for the detection of live Chlamydia. Blood was obtained by cardiac puncture with the animal under anesthesia. Serum was analyzed for anti-Chlamydia studies by ELISA and Western blots. A number of blood samples were also used to check for circulating live Chlamydia. In this case, mononuclear cells were separated using Lympholyte M (Cedarlane Laboratories, Hornby, ON).

Detection of live Chlamydia. Detection of live Chlamydia involved a two-step procedure. Synovial fluids, organ homogenates, and blood cell suspensions were centrifuged at $800 \mathrm{~g}$ for $30 \mathrm{~min}$ onto HeLa cell monolayers. After $48 \mathrm{~h}$ of incubation, the monolayers were examined under phase contrast microscopy for inclusion bodies. This provided an initial screening test. A secondary confirmatory culture was performed. The primary culture was harvested with a cell scraper, and $0.5 \mathrm{ml}$ of the cell suspension was applied onto a fresh monolayer of HeLa cells. The secondary culture was then spun down as before and examined after $48 \mathrm{~h}$.

Immunofluorescence studies. Snap frozen tissues were cryosectioned and fixed in methanol for $10 \mathrm{~min}$. Two Chlamydia immunofluorescence detection kits from Kallestad (Chaska, MN) were used. The Pathfinder Chlamydia Direct Antigen Detection System (\#624) uses an antibody to the outer membrane protein, MOMP, while the Pathfinder Chlamydia Confirmation System (\#532) uses an antibody to Chlamydia LPS. These are one-step tests with a labeled primary antibody and a counterstain. When examined under fluorescence microscopy, Chlamydia appears as green particles against a red counterstained background.

ELISA. ELISA plates were coated with a $10 \mu \mathrm{g} / \mathrm{ml}$ preparation of Chlamydia in a pH 9.6 carbonate-bicarbonate buffer overnight at $4^{\circ} \mathrm{C}$. A single batch of plates was prepared and kept frozen. Results reported represent duplicate analyses on two sets of animals.

Rat sera were diluted 1:200 in PBS containing 1\% BSA as blocking agent. $0.2 \mathrm{ml}$ was added to each well in triplicate. After $90 \mathrm{~min}$ of incubation at $37^{\circ} \mathrm{C}$, plates were washed and peroxidase-conjugated antibodies added. These secondary antibodies against rat $\mathrm{IgG}$ and IgA were obtained from Serotac Canada (Toronto, ON). They were diluted 1:5000 in the PBS with 1\% BSA. After a further 90-min incubation at $37^{\circ} \mathrm{C}$, the plates were washed and color developed with o-phenylenediamine $(0.4 \mathrm{mg} / \mathrm{ml})$ as substrate. Plates were read at 490 nm with an ELISA plate reader.

To obtain positive control sera, Lewis rats were immunized conventionally with a subcutaneous injection of about $5 \times 10^{5}$ CFUs of killed Chlamydia in complete Freund's adjuvant. 1 wk later, the rats were given a similar booster injection, again subcutaneously with incomplete Freund's adjuvant.

Western blot. Western blot analysis of anti-Chlamydial antibodies was carried as previously described (4). Briefly, C. trachomatis was electrophoresed using SDS-PAGE then electrotransferred onto nitrocellulose sheets for subsequent incubation with immune serum samples at a dilution of 1:100 for $90 \mathrm{~min}$ at RT. After washing, the strips were incubated with a peroxidase-conjugated anti-rat secondary antibody at a dilution of 1:5000 for $90 \mathrm{~min}$. The strips were developed with an Amersham ECL Western Blot Detection System and exposed to X-ray films (Amersham, Arlington Heights, IL).

Antibiotic treatments. Therapeutic modifications of the standard model of injecting Chlamydia-laden synoviocytes were performed using the antibiotics tetracycline (TCY) and ciprofloxacin (CFX). TCY $\mathrm{HCl}$ was obtained from Sigma, dissolved in PBS, and made fresh prior to each use. The dose of the antibiotic was calculated using reference standards from the Merck Veterinary Manual to be 2.7 $\mathrm{mg} /$ day.

The antibiotics were injected intramuscularly daily on different schedules. With schedule 1, TCY was administered on the same day as the intra-articular injection of synoviocytes, and then $7 \mathrm{~d}$ later. With schedule 2, TCY was administered $2 \mathrm{~d}$ prior to the joint injection and then daily for $9 \mathrm{~d}$. With schedule 3 , TCY was held until $48 \mathrm{~h}$ post-intra-articular injection, coincident with the clinical onset of arthritis. It was then injected daily for $5 \mathrm{~d}$. With schedule 4, daily TCY injections started $2 \mathrm{~d}$ prior to the synoviocyte injection but was stopped $48 \mathrm{~h}$ later, for a total of five injections.

CFX was obtained from Bayer (Etobicoke, ON) as an injectable liquid. The dosage of $2.75 \mathrm{mg} / \mathrm{d}$ was used, given by intramuscular injection. Two injection schedules were followed for CFX. With schedule 1, CFX was injected on the same day as the Chlamydia injection and then daily for $7 \mathrm{~d}$. With schedule 2, CFX injection was held until $48 \mathrm{~h}$ after the Chlamydia injection and then daily for a total of five injections. Results reported represent millimeters of swelling on three animals for each set of experimental conditions.

\section{Results}

Gross observations. After intra-articular injection of synoviocyte-packaged Chlamydia into the knee joints of Lewis rats, the first sign of arthritis appeared $48 \mathrm{~h}$ later with swelling of the injected joints. The swelling progressed over 7-10 d (Fig. 1). During the active phase of arthritis, the mobility of the animals was restricted. After $2 \mathrm{wk}$, there was a gradual decline in joint swelling and the animals were more active. At the third week postinjection, joint swelling could still be palpated. The 


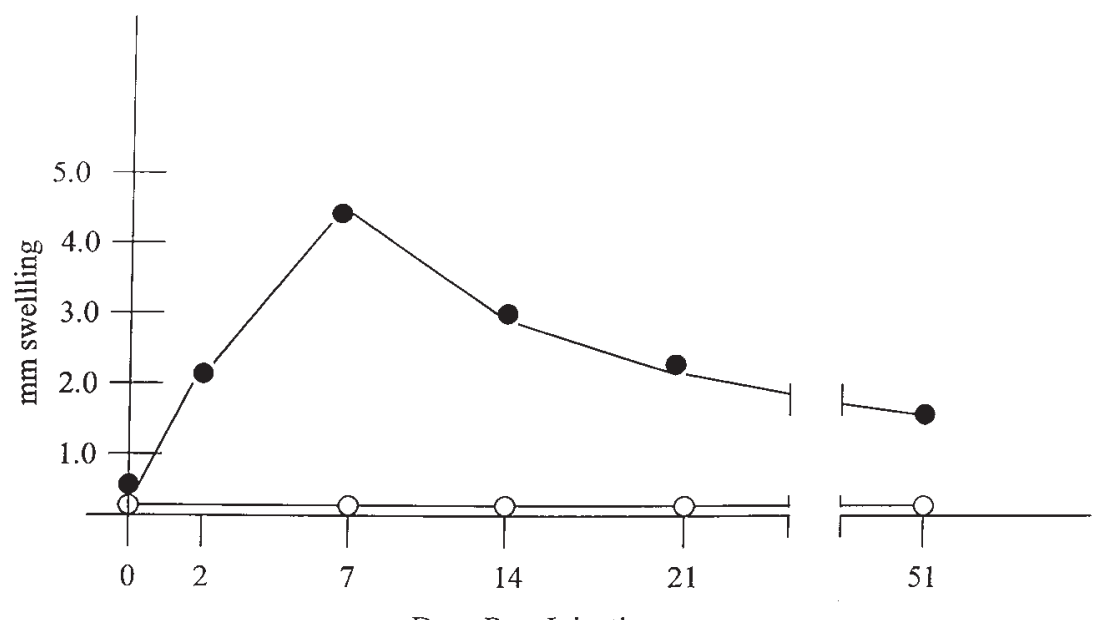

Days Post Injection
Figure 1. Time course of experimental Chlamydiainduced arthritis measuring the degree of swelling in the knee joint. The solid circles represent joints injected with synoviocyte-packaged Chlamydia. The open circles represent joints injected with unmodified synoviocytes. contralateral knee either injected with control uninfected Lewis synoviocytes or noninjected showed no clinical signs of arthritis at any time.

At $2,7,14,21$, and $50 \mathrm{~d}$ postinjection, a subset of rats was sacrificed for analysis. Their knee joints were removed, and the lateral width of the joints was measured before histological processing. The measurements are summarized in Table 1. The maximum swelling was observed on day 7 when the infected joints were on average about $50 \%$ larger than normal rat knees. Although the swelling diminished, it persisted through to day 50 when the animal was sacrificed.

Histology. Histological (H/E) evaluations of the longitudinal sections of the joint showed that $48 \mathrm{~h}$ after synoviocyte injection there was a significant infiltration of polymorphonuclear neutrophils (PMNs) accompanied by moderate hyperplasia of the synovial tissues (Fig. $2 A$ ). Early pannus develop- ment was observed, but cartilage and bone pathology were absent at this point. $1 \mathrm{wk}$ after injection, the knee joints were extensively infiltrated by PMNs (Fig. 2 B). Synovial hyperplasia and hypertrophy were extensive. The synovial spaces were filled by the hypertrophic tissues and the joint capsules were engorged. Pannus was more extensive. Early erosive cartilage and bone changes were seen. The leading edge of the erosion front consisted of fibroblast-like cells. There were changes in subchondral bone, and in some cases fibroblast-like cells had infiltrated bone marrow space. The histology at $14 \mathrm{~d}$ was similar.

By day 21, the synovial tissues were still markedly hypertrophic; however, the density of the leucocytes had diminshed (Fig. 2 C). Early fibrosis in the subsynovium was seen. The character of the infiltrating leucocytes started to change from PMNs to the appearance of mononuclear cells. Plasma cells were also evident. Cartilage dysplasia was seen with disruption
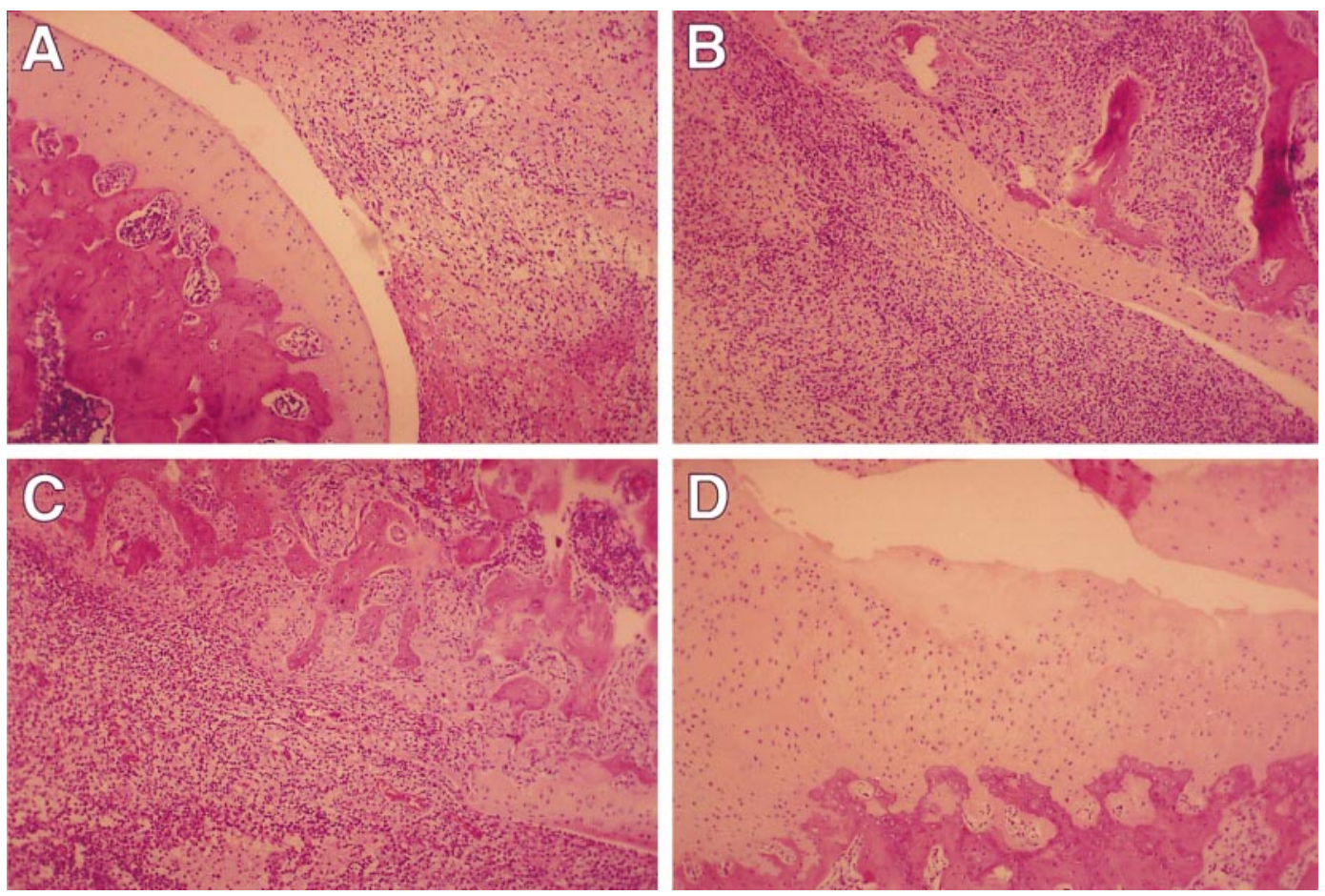

Figure 2. H/E histopathology of the evolution of joint inflammation. $(A)$ $2 \mathrm{~d} ;(B) 14 \mathrm{~d} ;(C) 21 \mathrm{~d}$; (D) $50 \mathrm{~d}$ postinjection. 
Table I. Composite Measurements of Lateral Width of Knees

\begin{tabular}{lrr}
\hline Days postinjection & Dimension in $\mathrm{mm} \pm 1 \mathrm{SD}$ & $n$ \\
\hline Normal controls & $8.52 \pm 0.45$ & 12 \\
2 & $10.50 \pm 0.65$ & 5 \\
7 & $12.42 \pm 1.06$ & 15 \\
14 & $11.60 \pm 0.64$ & 4 \\
21 & $10.48 \pm 0.43$ & 5 \\
34 & $9.95 \pm 0.35$ & 2 \\
50 & $10.22 \pm 0.40$ & 6 \\
& & \\
\hline
\end{tabular}

of the normal joint architecture and alteration of smooth articular surfaces. Cartilage regeneration was evident on the day 50 examination (Fig. $2 \mathrm{D}$ ). Chondrocytes were active with large lacunae containing multiple cells. The cartilage matrix was uneven and their surfaces were rough and distorted. The synovial tissues remained hypertrophic with an infiltration of mononuclear cells and patchy fibrosis.

Knees injected with uninfected synoviocytes only had slight transient inflammation at $48 \mathrm{~h}$ postinjection but had completely normalized at a day 7 examination. Uninjected contralateral joints had completely normal histology.

Detection of live Chlamydia. Using the two-step procedure, live Chlamydia were cultured from the synovial fluids of injected joints for up to $14 \mathrm{~d}$ (Table II). The cultures were negative by the third week. The control contralateral knees remained culture negative throughout. Spleen and liver samples were culture positive during the first week but were negative beyond $7 \mathrm{~d}$. Cultures of blood, lungs, and kidneys remained negative throughout.

Anti-Chlamydia antibodies. ELISA assay of antibody responses to intra-articular challenges is shown in Fig. 3. IgG titer was only slightly higher at day 7 postinjection and not significantly elevated until day 14 . There was no IgA response until the third week.

By Western blot, the preimmune sera showed no reactivity with Chlamydia (Fig. 4). At day 14, antibodies were detectable, binding primarily the $40 \mathrm{kD}$ MOMP as well as antigens at $58 \mathrm{kD}$ and $65 \mathrm{kD}$. The reactivity from chronic arthritis $(85 \mathrm{~d})$ detected an even broader range of antigens, including 26,32 , $38,40,58$, and $60 \mathrm{kD}$.
Table II. Results of Cultures for C. trachomatis in Selected Organs after Intra-Articular Injection (Number of Positive Cultures/Number of Animals Examined)

\begin{tabular}{lcccccc}
\hline $\begin{array}{l}\text { Days } \\
\text { postinjection }\end{array}$ & $\begin{array}{c}\text { Chlamydia-injected } \\
\text { knee }\end{array}$ & $\begin{array}{c}\text { Control-injected } \\
\text { knee }\end{array}$ & Spleen & Liver & Kidney & Lung \\
\hline 2 & $5 / 5$ & $0 / 5$ & $5 / 5$ & ND & ND & ND \\
7 & $11 / 11$ & $0 / 11$ & $11 / 11$ & $11 / 11$ & $0 / 2$ & $0 / 2$ \\
14 & $6 / 6$ & $0 / 6$ & $0 / 6$ & $0 / 6$ & $0 / 2$ & $0 / 2$ \\
21 & $0 / 6$ & $0 / 6$ & $0 / 6$ & $0 / 6$ & $0 / 2$ & $0 / 2$ \\
50 & $0 / 12$ & $0 / 12$ & $0 / 12$ & $0 / 12$ & ND & ND \\
& & & & & & \\
\hline
\end{tabular}

Immunofluorescence studies. Using immunofluorescence, Chlamydia antigens could be demonstrated in the synovial tissues and spleens of the rats $7 \mathrm{~d}$ postinjection (Fig. 5, $A$ and $B)$. Both LPS and MOMP were detected (Table III). Results from the spleen tissues $50 \mathrm{~d}$ postinjection indicated positive staining for MOMP (8/12 animals) and for LPS (9/12 animals), but only one synovial tissue was positive for MOMP at $50 \mathrm{~d}$ and none were positive for LPS.

In the 14-d postinjection spleen samples, a characteristic feature was observed (Fig. 5, $C$ and D). Chlamydia antigens, both LPS and MOMP, were reproducibly deposited in a ring pattern (Fig. 3). When the spleens were stained with $\mathrm{H} / \mathrm{E}$, the ring pattern corresponded anatomically to the marginal zone between the red and white pulp. This marginal zone is demarcated by reticular cells and is the site where capillaries leading out from the central arterial of the white pulp empty into the venous sinus of the red pulp.

Nonarticular injections. We examined whether dissemination from the knee joint to the liver and spleen was unique to the joints. Rats were injected with an equivalent dose of Chlamydia in Lewis fibroblasts intramuscularly into the posterior aspect of the rectus muscle just above the knee joint. Other rats were injected subcutaneously lateral to the knee. In neither case did clinical arthritis develop. No Chlamydia was isolated from the livers and spleens $7 \mathrm{~d}$ postinjection. No Chlamydia was recovered from the injected rectus muscle at $7 \mathrm{~d}$.

Inactivated Chlamydia. To determine whether the development of arthritis and joint pathology required viable microorganisms, heat-inactivated Chlamydia was injected intra-

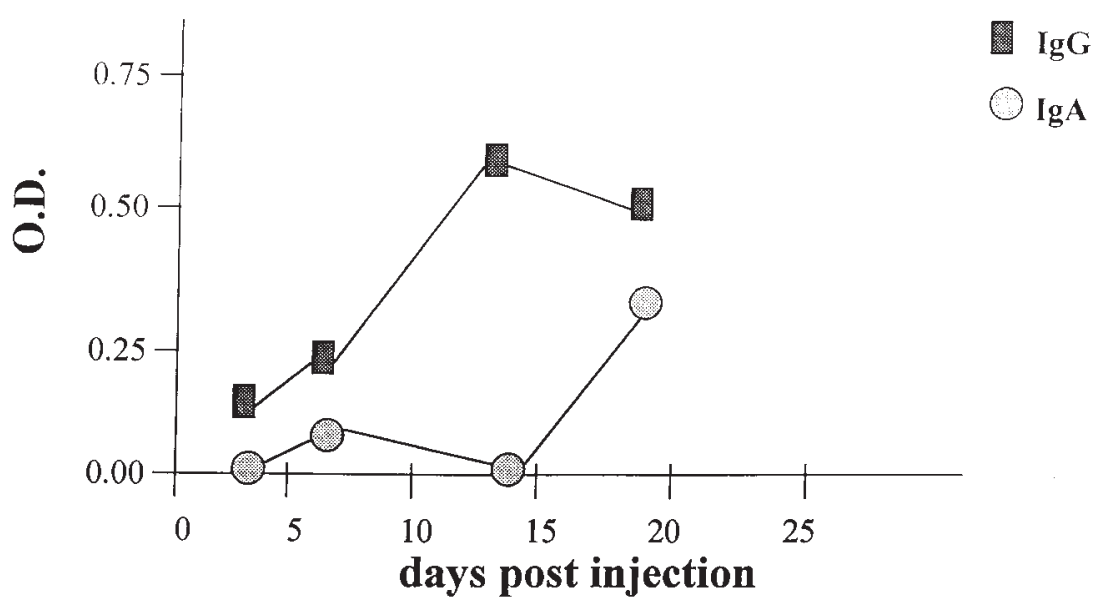

Figure 3. ELISA analysis of anti-Chlamydia antibodies during the course of arthritis. 


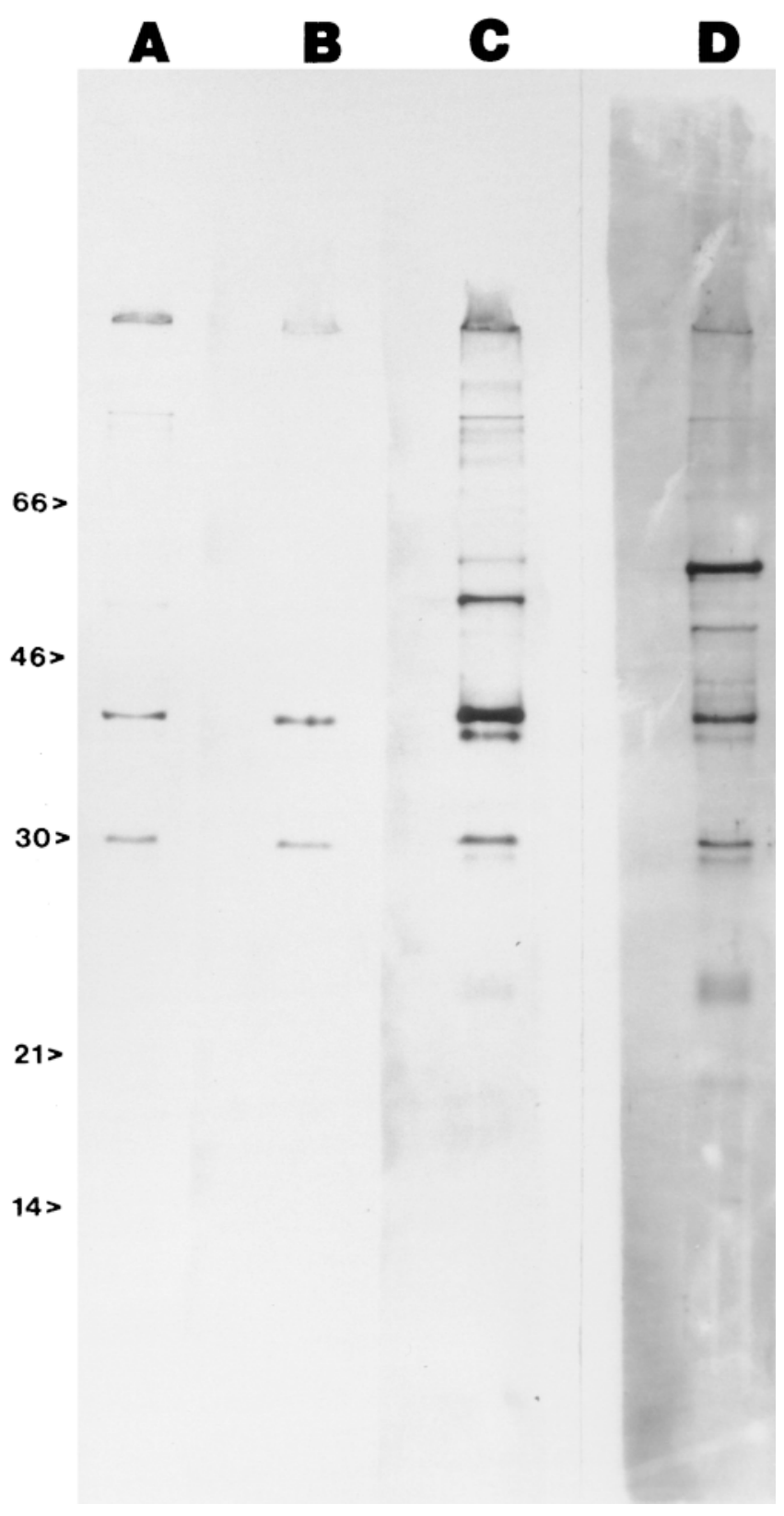

Figure 4. Western blot analysis of anti-Chlamydia antibodies in experimental and clinical Chlamydia-induced arthritis. Lanes $A, B$, and $C$ represent sequential serum samples from an animal with arthritis at 2,4 , and $8 \mathrm{wk}$, respectively. Lane $D$ represents serum reactivity in a patient with post-Chlamydia ReA.

articularly. Heat inactivation was carried out by raising the temperature of the Chlamydia-laden Lewis synoviocytes to $75^{\circ} \mathrm{C}$ for $10 \mathrm{~min}$ before being harvested for injection. No clinical arthritis developed and joint histology was normal $7 \mathrm{~d}$ postinjection. Immunofluorescence detected no LPS or MOMP in the synovial tissues of the injected joints.

Male versus female. When both male and female Lewis rats were injected, their clinical arthritis appeared to be identical. Live Chlamydia were isolated from the injected knee joints, liver, and spleen $7 \mathrm{~d}$ postinjection in both males and females.

Antibiotic treatment. All rats that were administered TCY were free of any sign of arthritis $7 \mathrm{~d}$ postintra-articular syno-
Table III. Results of Immunofluorescence Analysis on Various Organs (Number of Positive/Number of Animals Tested)

\begin{tabular}{ccccc}
\hline Days postinjection & Injected knee & Spleen & Liver & Lung \\
\hline $\begin{array}{llll}\text { Anti-MOMP } \\
7\end{array}$ & & & & \\
50 & $9 / 9$ & $9 / 9$ & $0 / 9$ & $0 / 9$ \\
Anti-LPS & $1 / 12$ & $8 / 12$ & $0 / 12$ & ND \\
7 & & & & \\
50 & $9 / 9$ & $9 / 9$ & $0 / 9$ & $0 / 9$ \\
& $0 / 12$ & $9 / 12$ & $0 / 12$ & ND \\
\hline
\end{tabular}

viocyte injections (Fig. 6). This included rats from all four schedules. Animals from schedule 3 started to show typical signs of arthritis $48 \mathrm{~h}$ after synoviocyte injections, but starting TCY treatment on this day eliminated all signs of arthritis. After sacrifice of the animals after $7 \mathrm{~d}$, no Chlamydia could be isolated from the injected knee joints, livers, or spleens. The lateral width of their knees was $8.8 \mathrm{~mm}(n=2)$ for schedule 1 rats, $8.7 \mathrm{~mm}(n=6)$ for schedule 2 rats, $10.0 \mathrm{~mm}$ for schedule 3 rats, and $9.0 \mathrm{~mm}(n=4)$ for schedule 4 rats. Only those joints from schedule 3 were slightly larger than normal. The clinical impact of TCY treatment on the late course of arthritis in varying schedules and varying doses has not been performed as yet. Histologically, none of the joints in the TCY-treated animals showed significant PMN infiltration. Instead, there was mild infiltration of mononuclear leukocytes. Only the synovial tissues from schedule 3 rats were moderately hypertrophic with more of a fibrous reaction than hypercellularity.

Contrary to TCY, CFX was not effective in modifying the Chlamydia-induced arthritis. All rats developed full-blown arthritis with average lateral joint widths of $12.3 \mathrm{~mm}(n=3)$ and $11.8 \mathrm{~mm}(n=2)$ for schedule 1 and 2 rats, respectively. Histologically, these were highly inflamed knees with extensive structural lesions. Live Chlamydia was isolated from all joints as well as from the spleens of these rats. The clinical impression was that CFX was not only ineffective but might have worsened the arthritis.

\section{Discussion}

Infection-triggered arthritis can follow several different pathways (19). CIA, while previously being classified as a reactive arthritis, is now regarded as being closer to a septic arthritis. This arthritis is in fact the most notable clinical example in the spondyloarthropathies of a syndrome which blurs the distinction between a septic process and a reactive one. There has been evidence from electron microscopy and PCR studies of synovial tissues of CIA that the organism resides in the joint in a metabolically quiescent state, but as such can constitute a local source of microbial antigens sufficient to trigger and sustain a local inflammatory response in the joint. But the cellular and cytokine host defenses against intra-articular Chlamydia and the mechanisms responsible for prompt versus delayed clearance of the organism have not been defined. In the present study, we have developed a model system in which to analyze these events systematically.

We have shown that human synoviocytes in culture can be invaded by arthritogenic organisms and provide suitable host cells to maintain intracellular bacterial growth (20). But in the 

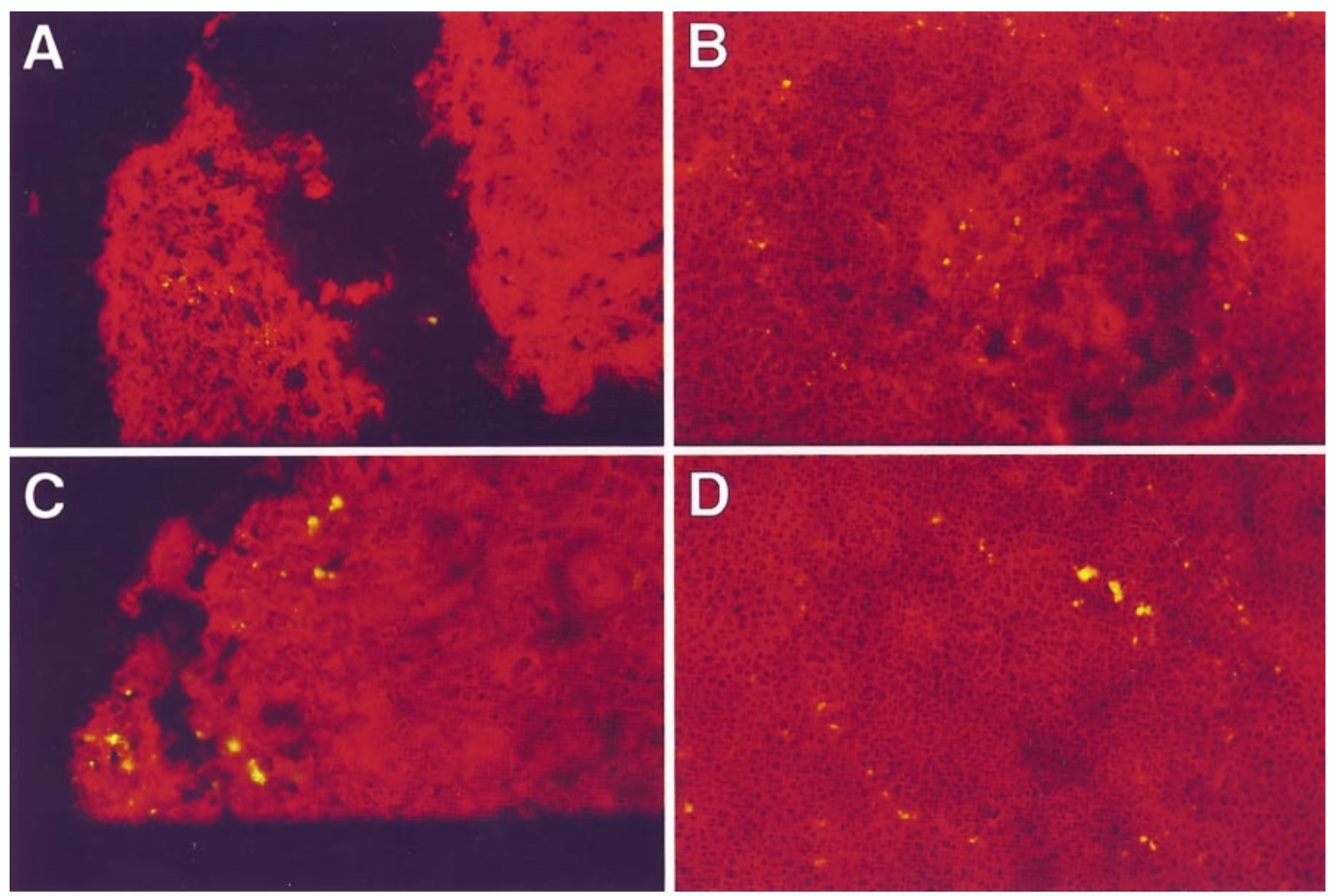

Figure 5. Immunofluorescent staining of synovial tissues ([A] anti-MOMP; $[B]$ anti-LPS) and spleen ([C] anti-MOMP; $[D]$ anti-LPS).

case of Chlamydia, the ambient synovial fluid in ReA is not toxic to the organisms, unlike the microbicidal effect such fluid has on the enteric gram-negative pathogens (18). The demonstration that synoviocytes can harbor Chlamydia and sustain its growth provided the groundwork for this study, which exploits this cell-pathogen interaction to generate an experimental model of CIA. Since Chlamydia is an obligate intracellular pathogen, a host cell delivery system more closely mimics the clinical situation in CIA. In our experience, elementary bodies purified by Renografin gradients, while appropriate for determining antigenicity, have greatly attenuated invasive properties and thus would not accurately reflect the biology of the organism residing in the joint in CIA.
Synoviocyte-packaged Chlamydia induce an intense cellular infiltration, which is predominantly neutrophilic early on but evolves to a mononuclear cell pattern over time. The earliest phase of clinical CIA is rarely amenable to descriptive analysis since patients are usually not seen in the first days of the onset of synovitis. Thus, analyses of synovial fluid in these arthropathies tend to be from more chronic patients (21-23). In the experimental model, there is significant cartilage injury during the acute intense synovitis with local erosive changes seen diffusely, and particularly at the cartilage-synovium interface. While there is evidence of cartilage regeneration following the acute injury, the predominant histopathology reflects cartilage dysplasia, with altered morphology and archi-

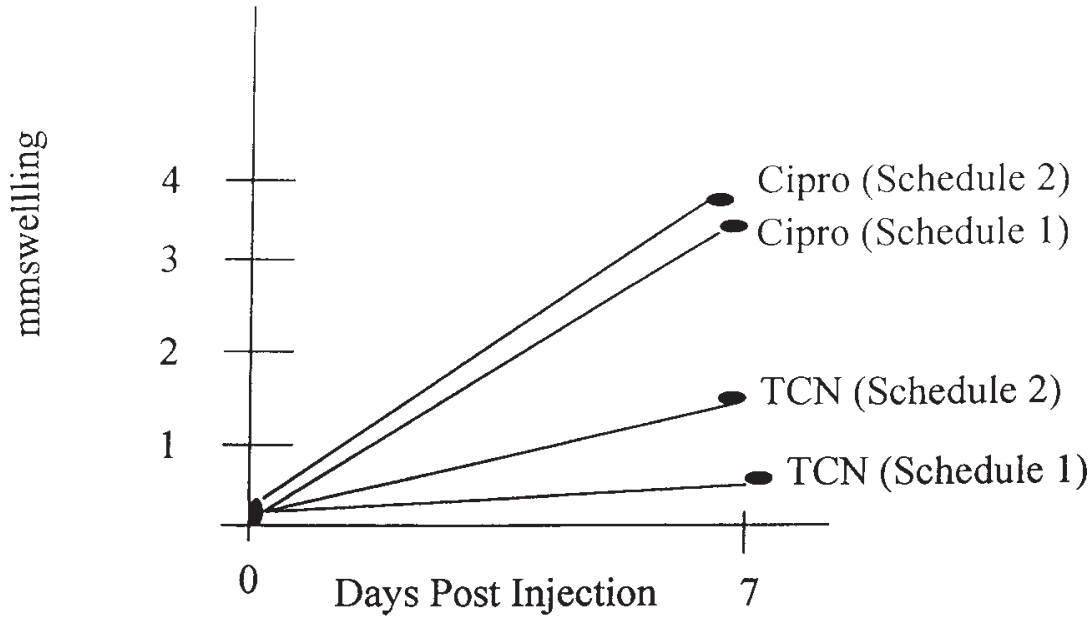

Figure 6. Antibiotic effect on acute arthritis. Schedule 1: antibiotic given coincident with Chlamydia, then daily $\times 7$. Schedule 2 : antibiotic given $2 \mathrm{~d}$ after Chlamydia, then daily $\times 5$. Antibiotics: tetracycline IM $2.7 \mathrm{mg} / \mathrm{d}$; ciprofloxacin IM $2.8 \mathrm{mg} / \mathrm{d}$. 
tecture. The late phase is characterized by a rough and irregular articular surface that has replaced the smooth congruent surfaces of the normal cartilage. Joint swelling persists at this late phase as well.

The late phase is characterized by lack of culture-positive Chlamydia and by largely negative immunofluorescence studies. One synovial tissue demonstrated positive immunofluorescence, indicating local persistence of the $40 \mathrm{kD}$ MOMP and suggesting a possible role for this antigen in perpetuating the local inflammation, but likely other chlamydial antigens are contributing to the persistence of the chronic inflammation. Our previous studies on reactivity of synovial fluid in Chlamydiainduced arthritis patients had demonstrated that MOMP was likely an important arthritogenic antigen (4). The late sera from the animals in the current study also implicates a $60-\mathrm{kD}$ molecular species which could represent Chlamydia heat shock protein. In vitro studies of interferon-treated Chlamydia have demonstrated that synthesis of this heat shock protein can be sustained under conditions of persistent Chlamydia infection (23). If there is a dominance of a Th1 response to the local antigen as has been suggested for patients with CIA (24), then a microenvironment with local interferon production could influence both the persistence and the antigenic expression of the resident organisms. A systematic analysis of cytokine expression in our experimental arthritis has not yet been performed.

There was significant dissemination of Chlamydia from the joints to liver and spleen in our animals. The immunofluorescence studies of the spleen indicate that the organisms lodge in the marginal zone at the interface of the red pulp and white pulp. Whether this reflects a distinctive spleen cell population in the region or the hemodynamic watershed at this site has not yet been resolved. It is of interest that recent studies in mice analyzing dissemination from the genitourinary tract have demonstrated a role for IFN- $\gamma$ in containing dissemination to extragenital sites (25). In our animals, the joint appears to be distinctively effective as a primary source of dissemination to spleen and liver, since comparable microbial loads delivered to juxta-articular soft tissues demonstrated no such dissemination. This suggests that if the organisms can gain access to the joint after a genitourinary infection, then the stage is set not only for joint inflammation but also perpetuation of the infection by dissemination to other sites.

This experimental model should allow a systematic analysis of factors implicated in human Chlamydia-induced arthritishost MHC, T cell subsets, local and systemic cytokine production, arthritogenic Chlamydia antigens - in a way that should provide new insights into pathogenesis and treatment of infection-induced arthropathies in general.

\section{Acknowledgments}

Grant support from the Arthritis Society and Medical Research Council.

\section{References}

1. Inman, R.D. 1994. Rheumatic disease etiology-environmental factors. In Rheumatology. P. Dieppe and J. Klippel, editors. Gower Medical Publishing, London. 14.1-14.6.

2. Granfors, K., S. Jalkanen, R. von Essen, R. Lahesmaa-Rantala, O. Iso- maki, K. Pekkola-Heino, R. Merilahti-Palo, R. Saario, H. Isomaki, and A. Toivanen. 1989. Yersinia antigens in synovial-fluid cells from patients with reactive arthritis. N. Engl. J. Med. 320:216-221.

3. Granfors, K., S. Jalkanen, A.A. Lindberg, O. Maki-Ikola, R. von Essen, R. Lahesmaa-Rantala, H. Isomaki, R. Saario, W.J. Arnold, and A. Toivanen. 1990. Salmonella lipopolysaccharide in synovial cells from patients with reactive arthritis. Lancet. 335:1224.

4. Inman, R.D., M.E.A. Johnston, B. Chiu, J. Falk, and M. Petric. 1987. Immunochemical analysis of immune response to Chlamydia trachomatis in Reiter's syndrome and nonspecific urethritis. Clin. Exp. Immunol. 69:246-254.

5. Bas, S., T. Cunningham, T.K. Kvein, A. Glenna, K. Melby, and T.L. Vischer. 1996. Synovial fluid and serum antibodies against Chlamydia trachomatis in different forms of arthritis: intra-articular IgA production in Chlamydia sexually acquired reactive arthritis. Br. J. Rheumatol. 35:548-552.

6. Gaston, J.S.H., K.H.O. Deane, R.M. Jecock, and J.H. Pearce. 1996. Identification of two Chlamydia trachomatis antigens recognized by synovial fluid $\mathrm{T}$ cells from patients with Chlamydia-induced reactive arthritis. J. Rheumatol. 23: $130-136$.

7. Schumacher, H.R., S. Magge, P.V. Cherian, J. Sleckman, S. Rothfuss, G. Clayburne, and M. Sieck. 1988. Light and electron microscopic studies on the synovial membrane in Reiter's syndrome: immunocytochemical identification of chlamydial antigen in patients with early disease. Arthritis Rheum. 31:937946.

8. Nanagara, R., F. Li, A. Beutler, A. Hudson, and H.R. Schumacher. 1995. Alteration of Chlamydia trachomatis biologic behavior in synovial membranes. Arthritis Rheum. 38:1410-1417.

9. Keat, A., J. Dixey, M. Osborn, C. Sonnex, and D. Taylor-Robinson. 1987. Chlamydia trachomatis and reactive arthritis: the missing link. Lancet. 1:72-74.

10. Taylor-Robinson, D., C.B. Gilroy, B.J. Thomas, and A.C. Keat. 1992. Detection of Chlamydia trachomatis DNA in joints of reactive arthritis patients by polymerase chain reaction. Lancet. 340:81-82.

11. Li, F., R. Bulbul, H.R. Schumacher, T. Kieber-Emmons, P.E. Callegari, J.M. von Feldt, D. Norden, B. Freundlich, B. Wang, V. Imonitie, C.P. Chang, I Nachamkin, D.B. Weiner, and W.V. Williams. 1996. Molecular detection of bacterial DNA in venereal-associated arthritis. Arthritis Rheum. 39:950-958.

12. Rahman, M.U., M.A. Cheema, H.R. Schumacher, and A.B. Hudson. 1992. Molecular evidence for the presence of Chlamydia in the synovium of patients with Reiter's syndrome. Arthritis Rheum. 35:521-529.

13. Hammer, M., E. Nellelnbreker, S. Hopf, E. Schmitz, K. Porschke, and H. Zeidler. 1992. Chlamydial rRNA in the joints of patients with Chlamydiainduced arthritis and undifferentiated arthritis. Clin. Exp. Rheumatol. 10:63-66.

14. Beutler, A.M., H.R. Schumacher, J.A. Whittum-Hudson, W.A. Salameh, and A.P. Hudson. 1995. In situ hybridization for detection of inapparent infection with Chlamydia trachomatis in synovial tissue of a patient with Reiter's syndrome. Am. J. Med. Sci. 310:206-213.

15. Lauhio, A., M. Leiresalo-Repo, J. Lahdevirta, P. Saikku, and H. Repo. 1991. Double-blind, placebo-controlled study of three-month treatment with lymecycline in reactive arthritis. Arthritis Rheum. 34:6-14.

16. Bardin, T., C. Enel, F. Cornelis, C. Salski, C. Jorgensen, R. Ward, and G.M. Lathrop. 1992. Antibiotic treatment of venereal disease and Reiter's syndrome in Greenland population. Arthritis Rheum. 35:190-194.

17. Toivanen, A., T. Yli-Kerttual, R. Luukkainen, R. Merilahti-Palo, K. Granfors, and J. Seppala. 1993. Effect of antimicrobial treatment on chronic reactive arthritis. Clin. Exp. Rheumatol. 11:301-307.

18. Inman, R.D., and B. Chiu. 1996. Comparative microbicidal activity of synovial fluid on arthritogenic organisms. Clin. Exp. Immunol. 104:80-85.

19. Inman, R.D., A. Perl, and P.E. Phillips. 1997. Infectious agents in chronic rheumatic diseases. In Arthritis and Allied Conditions, 13th Edition. W. Koopman, editor. Lea and Febiger, Philadelphia. 585-608.

20. Inman, R.D., and U. Payne. 1997. Clearance of intracellular bacteria by synoviocytes reflects a bimodal pattern among spondyloarthropathy patients. Arthritis Rheum. 40:s143.

21. Inman, R.D., M.E.A. Johnston, and M.H. Klein. 1987. Analysis of serum and synovial fluid IgA in Reiter's syndrome and reactive arthritis. Clin. Immunol. Immunopathol. 43:195-204.

22. Bas, S., R. Griffais, T.K. Kvien, A. Glennas, K. Melby, and T.L. Vischer. 1995. Amplification of plasmid and chromosome Chlamydia DNA in synovial fluid of patients with reactive arthritis and undifferentiated spondyloarthropathies. Arthritis Rheum. 38:1005-1013

23. Beatty, W.L., G.I. Byrne, and R.P. Morrison. 1993. Morphologic and antigenic characterization of interferon- $\gamma$ mediated persistent Chlamydia trachomatis infection in vitro. Proc. Natl. Acad. Sci. USA. 90:3998-4002.

24. Simon, A.K., E. Seipelt, P. Wu, B. Wenzel, J. Braun, and J. Sieper. 1993. Anlaysis of cytokine profiles in synovial $\mathrm{T}$ cell clones from Chlamydial reactive arthritis patients: predominance of the $\mathrm{Th}_{1}$ subset. Clin. Exp. Immunol. 94:122126

25. Cotter, T.W., K.H. Ramsey, G.S. Miranpuri, C.E. Poulsen, and G.I Byrne. 1997. Dissemination of Chlamydia trachomatis chronic genital tract infection in gamma interferon gene knockout mice. Infect. Immun. 65:2145-2152. 